University of Nebraska - Lincoln

DigitalCommons@University of Nebraska - Lincoln

Faculty Publications, Department of Psychology

Psychology, Department of

2015

\title{
Age and Lineup Type Differences in the Own-Race Bias
}

\author{
Lindsey E. Wylie \\ University of Nebraska-Lincoln, slwylie@unomaha.edu \\ Shaina Bergt \\ University of Nebraska-Lincoln \\ Joshua Haby \\ University of Nebraska-Lincoln \\ Eve M. Brank \\ University of Nebraska-Lincoln, ebrank2@unl.edu \\ Brian H. Bornstein \\ University of Nebraska-Lincoln, bbornstein2@unl.edu
}

Follow this and additional works at: https://digitalcommons.unl.edu/psychfacpub

Part of the Law Commons, Psychology Commons, and the Sociology Commons

Wylie, Lindsey E.; Bergt, Shaina; Haby, Joshua; Brank, Eve M.; and Bornstein, Brian H., "Age and Lineup Type Differences in the Own-Race Bias" (2015). Faculty Publications, Department of Psychology. 970. https://digitalcommons.unl.edu/psychfacpub/970

This Article is brought to you for free and open access by the Psychology, Department of at DigitalCommons@University of Nebraska - Lincoln. It has been accepted for inclusion in Faculty Publications, Department of Psychology by an authorized administrator of DigitalCommons@University of Nebraska - Lincoln. 
Published in Psychology, Crime E Law 21:5 (2015), pp. 490-506; doi: 10.1080/1068316X.2014.989173 Copyright (C) 2014 Taylor \& Francis. Used by permission.

Submitted August 6, 2014; accepted October 29, 2014; published online December 23, 2014.

\title{
Age and Lineup Type Differences in the Own-Race Bias
}

\author{
Lindsey E. Wylie, Shaina Bergt, Joshua Haby, Eve M. Brank, \\ and Brian H. Bornstein
}

Department of Psychology, University of Nebraska-Lincoln, Lincoln, Nebraska, USA

Corresponding author - Lindsey E. Wylie, email lwylie@huskers.unl.edu

\begin{abstract}
The own-race bias (ORB) suggests that recognition for faces of one's own race is superior to recognition of other-race faces. A popular explanation for the ORB is amount of interracial contact, which may have cohort effects for older and younger adults. We compared White younger and older adults on the ORB utilizing a hybrid facial recognition and full diagnostic lineup (i.e., simultaneous and sequential target absent and target present lineups) paradigm. Both younger and older adults demonstrated an ORB. Signal detection estimates suggest younger adults compared to older adults have better discrimination accuracy for own-race over other-race faces. Interracial contact did not explain recognition for younger adults but was related to a shift in response criterion for older adults.
\end{abstract}

Keywords: own-race bias, older adults, lineup type, contact hypothesis, signal detection

A recent examination of Innocence Project exoneration cases found that of the 190 documented exonerations due to eyewitness misidentification, 93 (49\%) involved cross-racial identification (Garrett, 2011). Although it is impossible to know whether these misidentifications were due to inaccurate cross-racial identification, a consistent body of literature suggests that our memory for own-race faces is better than our memory for other-race faces (Meissner \& Brigham, 2001; Sporer, 2001). This phenomenon, known as the own-race bias $(\mathrm{ORB})$ or cross-race effect, is widely recognized within psychological research as a potential factor in eyewitness misidentifications (for a review, see Brigham, 2008; Brigham, Bennett, Meissner, \& Mitchell, 2007; Meissner \& Brigham, 2001). Courts have also recognized 
the unreliability of cross-race identifications (e.g., Smith v. State, 2005; State v. Henderson, 2011), noting that "[c]ross-racial recognition continues to be a factor that can affect the reliability of an identification" (State v. Henderson, 2011, p. 907).

A popular explanation for the ORB is that interracial contact contributes to individuals' abilities to distinguish own-race faces in memory better than other-race faces in both the face recognition paradigm (e.g., Byatt \& Rhodes, 1998; Chiroro, Tredoux, Radaelli, \& Meissner, 2008; MacLin, Van Sickler, MacLin, \& Li, 2004; Slone, Brigham, \& Meissner, 2000) and applied lineup paradigm (e.g., Brigham, Maass, Snyder, \& Spaulding, 1982; Platz \& Hosch, 1988). This explanation is referred to as the "contact hypothesis," which postulates that the ORB increases as social contact with other races decreases (Brigham et al., 1982; Cross, Cross, \& Daly, 1971) because of a failure to select diagnostic features when encoding other-race faces (Brigham \& Malpass, 1985; Goldstein \& Chance, 1985; McDonnell, Bornstein, Laub, Mills, \& Dodd, 2014; Meissner \& Brigham, 2001). As a result of desegregation and improved interracial relations over the past several decades, researchers have proposed that increased exposure to other races may have generated cohort effects (Chance \& Goldstein, 1996) in the amount of interracial contact that older and younger adults experience. If so, these cohort effects, as well as data suggesting that social relationships become more narrowed as we age (Carstensen, Isaacowitz, \& Charles, 1999), may contribute to cross-sectional differences in the ORB due to age.

To date, most ORB research examining age differences has focused on children (e.g., Bennett \& Brigham, 2005; Cross et al., 1971; Feinman \& Entwisle, 1976; Pezdek, BlandonGitlin, \& Moore, 2003). Only one known study has specifically examined the ORB in older adults over the age of 60 (i.e., Brigham \& Williamson, 1979). Utilizing a face recognition paradigm, Brigham and Williamson (1979) found evidence of the ORB for both Black and White older adults (aged 60-84, $M=72$ ); however, because they did not include a younger adult sample, comparisons based on age were not possible. Instead, Brigham and Williamson compared results from this older adult sample to a younger adult sample exposed to the same stimuli in a previous study (Brigham \& Barkowitz, 1978). This comparison suggested that both samples exhibited an ORB (a correlation of $r=.82, p<.02$; Brigham \& Williamson, 1979), but the moderating effects of age group could not be tested.

Given that interracial contact is thought to result in problems with encoding the diagnostic features of other races (Brigham \& Malpass, 1985; Goldstein \& Chance, 1985; Meissner \& Brigham, 2001), age may also contribute to an ORB because aging may influence identification decisions (e.g., Bartlett \& Memon, 2007; Bornstein, 1995; Wylie et al., 2013). In general, older adults make more errors than younger adults in both sequential and simultaneous lineups (Steblay, Dysart, \& Wells, 2011). A consistent response pattern for older adults explains this deficit; although older and younger adults produce similar hit rates in target present (TP) lineups, older adults generally produce more false alarms in target absent (TA) lineups compared to younger adults (e.g., Bartlett \& Leslie, 1986; Bornstein, 1995; Fulton \& Bartlett, 1991; Memon \& Bartlett, 2002; Searcy, Bartlett, \& Memon, 1999; Wilcock $\&$ Bull, 2010). A recent meta-analysis by Steblay et al. (2011) suggests that older adults may benefit from simultaneous lineups when the target is present, and from sequential lineups when the target is absent; however, false choosing rates (i.e., selecting a foil) are still quite 
high for both types of lineups (50\% for sequential and $75 \%$ for simultaneous) and are generally higher than for younger adults. One explanation is that older adults may use familiarity-based recognition, rather than recollection-based recognition because normal aging affects recollection but not familiarity abilities (Yonelinas, 2002). Using familiarity-based recognition may result in better performance on simultaneous TP lineups when a relative judgment is required but worse performance when the target is absent and target-replacement foils are matched to be similar to the target.

At the time of Meissner and Brigham's (2001) review of cross-racial identification research, few studies utilized a lineup identification paradigm and of those that did utilize lineups, they were limited to simultaneous TP lineups. Given that the ORB is often observed in false alarms to nontarget faces (Meissner \& Brigham, 2001; Slone et al., 2000; Sporer, 2001), it is unfortunate that few studies employed a design that allows for comparisons of hits (TP lineups) and false alarms (TA lineups). In acknowledging the impact that the ORB may have on hits and false alarm rates, some researchers have utilized a hybrid design whereby participants are presented with multiple target faces (facial recognition memory paradigm) followed by a lineup presentation paradigm with simultaneous TA and TP lineups (Evans, Marcon, \& Meissner, 2009; Jackiw, Arbuthnott, Pfeifer, Marcon, \& Meissner, 2008). Although the hybrid design is still less ecologically valid than a witnessed event (followed by a lineup), it is more naturalistic than the pure facial recognition paradigm; moreover, comparisons of the different research paradigms have shown comparable effects, with effects in many cases larger for more naturalistic, eyewitness studies than for facial recognition studies (Penrod \& Bornstein, 2007).

The hybrid design has the advantage of providing multiple data points, allowing for additional analyses such as calculation of calibration or signal detection theory (SDT) estimates across conditions (e.g., Evans et al., 2009; Weber \& Brewer, 2004). SDT separates respondents' memory performance for presented and not-presented stimuli into discrimination accuracy, or the ability to recognize presented stimuli and correctly reject nonpresented stimuli; and response criterion (i.e., response bias), or the degree of evidence a respondent needs to indicate a stimulus has been previously presented. In general, discrimination accuracy is influenced by the quality of the memory representation (Meissner, Tredoux, Parker, \& MacLin, 2005). For example, research has found that increasing encoding strength through context reinstatement (Evans et al., 2009) or presenting faces more than once (Meissner et al., 2005) improved discrimination accuracy but did not elicit a response criterion shift. On the other hand, response criterion is influenced by social factors that create a tendency to respond in a certain manner (Meissner et al., 2005). Across three studies, Meissner et al. (2005) found that lineup type influenced response criterion such that sequential lineups resulted in more conservative responding than simultaneous lineups. These authors also found that other social factors, such as lineup instructions (Meissner et al., 2005, exp. 2) and lineup size (Meissner et al., 2005, exp. 3), influenced response criterion.

Although studies have indicated that SDT estimates provide insight into the potential mechanisms for the ORB, research has not yet examined SDT estimates in the ORB utilizing the "full diagnostic design" where both lineup type (sequential and simultaneous) and target absence/presence are fully randomized (Meissner et al., 2005; Steblay et al., 2011). 
Employing a full diagnostic design within this hybrid facial recognition/lineup paradigm is important given that hits, false alarms, discrimination accuracy, and response criterion are affected both by other-race identification and by lineup type. For instance, the ORB manifests as a "mirror-effect" pattern, such that other-race faces receive both fewer hits and more false alarms (Glanzer \& Adams, 1990). Consistent with this effect, the ORB also contributes to poorer discrimination accuracy and a more liberal response criterion than own-race faces (Meissner \& Brigham, 2001; Meissner et al., 2005). Likewise, simultaneous lineups result in more overall selections (i.e., higher choosing rates, or a more liberal response criterion) compared to sequential lineups (e.g., Meissner et al., 2005; Memon \& Bartlett, 2002; Memon \& Gabbert, 2003a, 2003b; Palmer \& Brewer, 2012; see Steblay et al., 2011 for a review). In TP lineups, more overall selections equates to more hits (correct identifications), but in TA lineups more overall selections results in more false alarms (mistaken identifications; Steblay et al., 2011).

\section{Current Research}

The present research investigated the ORB in a sample of older and younger adults using a hybrid version of the standard facial recognition paradigm and lineup identification paradigm, which allows for the calculation of signal detection estimates (Evans et al., 2009; Jackiw et al., 2008). It is important to examine lineup administration effects in the ORB not only because of the increasing adoption of sequential lineups (Klobuchar, Steblay, \& Caligiuri, 2006; U.S. v. Brown, 2006; U.S. v. Ford, 2012; Wells, Memon, \& Penrod, 2006) but also because related cognitive processes (e.g., a criterion shift) might underlie age differences in performance based on the ORB and lineup presentation. To extend previous research, we employed a full diagnostic design to examine whether TA and TP simultaneous and sequential lineup presentations moderated the ORB (hits, false alarms, discrimination accuracy, and response criterion) in a lineup identification paradigm. Furthermore, because age differences between older and younger adults have not yet been directly compared, this study will allow for cohort comparisons and to test whether interracial contact mediates age and the ORB.

\section{Method}

\section{Participants}

The sample $(N=155)$ included White older adults $(n=63$; aged $60-91 ; M$ age $=72 ; S D=3.17$; $73 \%$ women) and White younger adults ( $n=92$; all under age 30; $M$ age $=20, S D=7.22 ; 70 \%$ women). As part of a larger unrelated study that interviewed older and younger adults on issues related to elder caregiving, all of the older adults and some of the younger adults ( $n$ = 17) were paid $\$ 15$ for their participation and were recruited from a community member participant pool located in a Midwestern city. The remainder of the younger adult sample included college students at a Midwestern university in the same city who earned psychology course credit in exchange for their participation. Although fully crossed studies of the ORB (i.e., multiple racial/ethnic groups of participants and multiple target races/ethnici- 
ties) are preferable, studies involving participants of one race are still informative and important (e.g., Evans et al., 2009; Marcon, Meissner, Frueh, Susa, \& MacLin, 2010; Pezdek, O’Brien, \& Wasson, 2012).

\section{Materials}

Photographs for initial presentation and lineups

The 14 initial presentation photographs depicted young men and women in their early 20s wearing their own clothes and smiling; each photograph was in color, homogeneous in lighting and size, and included their head and shoulder (Bornstein, Laub, Meissner, \& Susa, 2013; Doob \& Kirshenbaum, 1973; Evans et al., 2009). The ratio of male to female photographs was constant across race. The photographs have been used in previous research where they were pretested to ensure that attractiveness and distinctiveness were comparable across the Black and White faces. Although there is some evidence for an ownage bias in laboratory studies that could affect age differences (e.g., Wright \& Stroud, 2002), the age of the targets was held constant because few real-world identifications with stranger-suspects involve the identification of older adult suspects by young adult witnesses (Valentine, Pickering, \& Darling, 2003). Each photograph was shown for 3.5 seconds, with a 1-second interstimulus interval between the photographs (Evans et al., 2009).

Lineup photographs were taken at the same time as initial presentation photographs so appearance was constant. In the lineup photographs, all targets and foils wore the same color shirt and did not smile. The six-person TA and TP lineups were constructed following the two-step procedure suggested by Koehnken, Malpass, and Wogalter (1996). Lineup members were first chosen for their match to the target's description and then chosen based on their similarity to each other. A pilot study was conducted to determine the facial similarities between foils and targets. Students $(N=18)$ from an undergraduate psychology class rated 16 photographs based on similarity to the six targets on a 10-point scale $(1=$ not at all similar to $10=$ very similar). Based on mean similarity ratings, targets and foils were paired so that target photographs in the TP lineups were each replaced by the target's most similar foil photograph in the TA lineup. Foils and targets were not repeated in any of the lineups.

\section{Independent measures}

Contact with other groups

Contact with other races/ethnicities was measured with the Multicultural/Multiracial Experience Inventory (MEI; Ramirez, 1991) modified for White participants. The MEI is a 23item scale that measures individuals' past and present interactions with other racial/ethnic groups, which has been used in prior ORB research (e.g., Bornstein et al., 2013) and is described as a measure of affiliation with other races, as opposed to preferences for other races (Zane \& Mak, 2003). Higher scores on the MEI indicate more interactions with people of other groups. We used series mean replacements for any missing data of three items or fewer (data with more than three missing items were dedicated as missing; $n$ older adults $=10$, $n$ younger adults $=2$ ). A score was computed for each participant based on the author's 
recommended scoring technique (see Ramirez, 1991; Cronbach's $\alpha=.72$ ). Table 1 includes descriptive statistics by age group.

\begin{tabular}{lccccc}
\hline \multicolumn{7}{l}{ Table 1. Descriptive data on independent measures by age group } \\
\hline & $N$ & $M$ & $S D$ & Min & Max \\
\hline Younger adults & 93 & & & & \\
$\quad$ Verbal ability & & 27.47 & 3.90 & 20.00 & 38.00 \\
Contact with other groups & & 41.87 & 7.74 & 29.00 & 66.00 \\
Confidence & 4.61 & 1.04 & 1.67 & 6.58 \\
Older adults & & & & \\
$\quad$ Verbal ability & & 34.17 & 3.47 & 25.50 & 39.00 \\
$\quad$ Contact with other groups & & 38.94 & 6.11 & 27.00 & 54.00 \\
Confidence & & 4.06 & 1.25 & 1.00 & 6.75 \\
\hline
\end{tabular}

Note: Range for verbal ability (0-40); range for contact with other groups (23-115); range for confidence (1-7).

\section{Verbal intelligence}

To ensure the older adult sample did not have cognitive impairment, participants completed the Shipley Institute of Living Scale (Shipley, 1967; Zachary, 1991) as a measure of verbal intelligence. The Shipley is a 40 -stimuli multiple-choice task that measures individuals' ability to choose synonyms for English words that become increasingly difficult. Response options for each word include four synonyms. Higher scores indicate higher verbal ability. There were significant differences by age group, $\mathrm{F}(1,153)=120.79, p<.001, \eta^{2}=.40$, with older adults having higher verbal intelligence than younger adults (see Table 1), a common finding in the aging literature (e.g., Rice \& Meyer, 1986). No participants demonstrated an inability to successfully complete the measure; thus, all were retained in the sample.

Visual acuity

Visual acuity was tested with any corrective lenses using the Snellen Eye chart. All participants in both samples had acceptable visual acuity; thus, all were retained in the sample.

\section{Dependent measures}

\section{Lineup accuracy}

Following each lineup, participants indicated whether one of the photographs was previously viewed during the initial presentation. Participants were explicitly told to select only one foil per lineup; however, some participants still made more than one selection. Similar to previous research, if a participant indicated "yes" and selected a photograph more than once, we used the first "yes" in each lineup (Gronlund, Goodsell, \& Andersen, 2012). 


\section{Confidence}

Following the presentation of each lineup, participants indicated their level of confidence on a 7-point scale ranging from 1 (not at all confident) to 7 (completely confident), with the question, "How confident are you in your decision for this lineup?" Participants made only a single overall confidence rating for each lineup, despite making six decisions within the sequential lineup, for purposes of comparability with the simultaneous lineup condition (Gronlund et al., 2012).

\section{Procedure}

The design was a 2 (age group: older adult vs. younger adult) $\times 2$ (lineup type: simultaneous vs. sequential lineup) $\times 2($ TA vs. TP $) \times 2$ (target race: White vs. Black) mixed factorial design. All variables were between groups except for TA-TP and target race. Following the procedures of Evans et al. (2009), participants saw a series of faces followed by a series of lineups. Participants were presented with a race block that included either seven photographs of Black faces or seven photographs of White faces (blocks were counterbalanced by race and photographs were presented in random order). Following the initial presentation of photographs for each race block, participants completed filler tasks that included demographics and the Multicultural Exposure Inventory (MEI; Ramirez, 1991) that measures individuals' past and present interactions with other racial/ethnic groups. Because race blocks were counterbalanced, the filler tasks were equally presented during each of the race blocks.

Next, participants were randomly assigned to either the simultaneous or sequential lineup condition where they received 6-person lineups for each race, resulting in 12 total lineups across both race blocks. Each lineup had either one TP or no TA previously seen face. Thus, each participant made decisions on three TA own-race lineups, three TP ownrace lineups, three TA other-race lineups, and three TP other-race lineups. This "multiple lineup" procedure combines desirable features of both the face recognition and eyewitness lineup paradigms, using a forensically valid recognition task while providing multiple judgments, thereby enabling calculation of signal detection measures (Evans et al., 2009; Meissner et al., 2005).

Participants either identified a lineup member as previously observed in the initial presentation or rejected the lineup. For each lineup, participants provided a confidence rating on a 7-point scale. At the end of the procedure, participants completed the visual acuity exam and the test of verbal intelligence described in the measures section.

\section{Results}

Table 2 presents mean recognition measures for own- and other-race faces. Hits and false alarms were used to calculate the signal detection estimates $A_{z}$ for discrimination accuracy and $c$ for response criterion (Donaldson, 1992; Stanislaw \& Todorov, 1999), using a correction score when rates were $0(0.01)$ or $1(0.99)$. Higher values of $A_{z}$ indicate that a participant was better able to discriminate between previously seen targets (in the TP lineup) and foils (in the TA lineup). $A_{z}$ is a monotonic transformation of $d^{\prime}$, which has been found to have greater accuracy, precision, and more robust to changes in sample size than $A^{\prime}$ (Pastore, 
Crawley, Berens, \& Skelly, 2003; Verde, Macmillan, \& Rotello, 2006). Negative values of $c$ indicate a response criterion toward saying "yes" and selecting a photograph, and a positive value indicates a response bias toward saying "no" and not selecting a photograph. We did not analyze the rates of choosing an innocent foil in TP lineups or the target replacement in the TA lineup because our analyses, like previous research, focused on the aggregate rates of false alarms and hits (Evans et al., 2009; Jackiw et. al., 2008).

\begin{tabular}{|c|c|c|c|c|}
\hline & \multicolumn{2}{|c|}{ White lineups } & \multicolumn{2}{|c|}{ Black lineups } \\
\hline & $M$ & $S D$ & $M$ & $S D$ \\
\hline \multicolumn{5}{|l|}{ Younger adults } \\
\hline Hits & 0.64 & 0.30 & 0.52 & 0.31 \\
\hline False alarms & 0.37 & 0.32 & 0.62 & 0.32 \\
\hline \multicolumn{5}{|l|}{ Older adults } \\
\hline Hits & 0.48 & 0.33 & 0.33 & 0.30 \\
\hline False alarms & 0.61 & 0.35 & 0.70 & 0.31 \\
\hline
\end{tabular}

\section{Discrimination accuracy}

First, a mixed-model analysis of variance (ANOVA) was conducted to examine the effects of age on discrimination accuracy for White versus Black lineups. There was a main effect for age group, $F(1,153)=29.03, p<.001, \eta^{2}=.16$, such that younger adults $(M=0.57, S E=$ $0.03)$ had better discrimination accuracy than older adults $(M=0.33, S E=0.03)$. As expected and consistent with prior literature (Evans et al., 2009; Meissner \& Brigham, 2001), a significant main effect for race, $F(1,151)=51.01, p<.001, \eta^{2}=.25$, was observed for participants' discrimination accuracy, in which discrimination accuracy was better for White lineups $(M=0.55, S E=0.03)$ than for Black lineups $(M=0.35, S E=0.03)$. The age differences and $\mathrm{ORB}$, however, were qualified by a significant two-way age group $\times$ race interaction $F(1,153)=3.86, p<.05, \eta^{2}=.03$. As displayed in Figure 1, both age groups' discrimination accuracy was significantly greater for White lineups than Black lineups (according to Least Significant Difference [LSD] test, $p<.05$ ); however, younger adults demonstrated a larger difference in discrimination accuracy between White and Black lineups than older adults. 


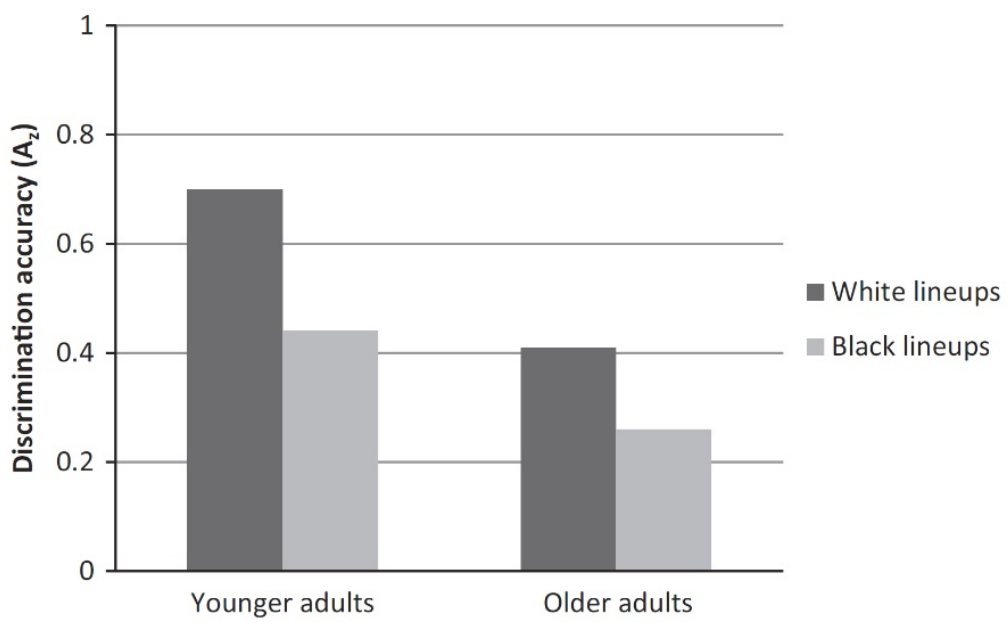

Figure 1. Mixed-model ANOVA for older versus younger adults' discrimination accuracy for White and Black lineups.

To examine the effects of age and lineup type for both Black and White lineups on discrimination accuracy, two separate two-way ANOVAs were conducted. For White lineups, there were significant age, $F(1,155)=36.88, p<.001, \eta^{2}=.20$, and lineup type, $F(1,155)=19.31$, $p<.001, \eta^{2}=.11$, main effects. These main effects, however, were qualified by a significant age $\times$ lineup type interaction $F(1,155)=9.51, p<.01, \eta^{2}=.06$. Although previous research found no discrimination accuracy differences by lineup type (Meissner et al., 2005), discrimination accuracy was significantly better for White simultaneous lineups (younger adults: $M=0.73, S E=0.04$; older adults: $M=0.58, S E=0.05$ ) as compared to sequential lineups (younger adults: $M=0.67, S E=0.04$; older adults: $M=0.21, S E=0.06$ ). For Black lineups, there were significant age, $F(1,155)=12.42, p<.01, \eta^{2}=.08$, and lineup type, $F(1,155)=9.51, p<.01, \eta^{2}=.06$, main effects; but no significant age $\times$ lineup type interaction $F(1,155)=0.05, p=.82, \eta^{2}=.01$. Similarly, discrimination accuracy for Black lineups was significantly better for simultaneous lineups (younger adults: $M=0.52, S E=0.05$; older adults: $M=0.33, S E=0.05$ ) as compared to sequential lineups (younger adults: $M=0.35$, $S E=0.05$; older adults: $M=0.18, S E=0.06$ ).

\section{Response criterion}

Overall, participants demonstrated a response bias toward saying "yes" (more liberal response) to having previously seen a target in the lineup as indicated by an overall negative mean value (-0.15) and negative values for most conditions. A mixed-model ANOVA was conducted to examine the effects of age on response criterion for White versus Black lineups. Contrary to our expectations and previous research (Evans et al., 2009), there were no significant response criterion main effects for race, $F(1,153)=0.76, p=.39, \eta^{2}=.01$. There was also no significant effect for age group, $F(1,153)=0.02, p=.88, \eta^{2}=.01$; however, there was a significant two-way race $\times$ age group interaction $F(1,151)=3.83, p=.05, \eta^{2}=.02$. As displayed in Figure 2, younger adults had a significantly more liberal response bias for Black lineups (according to LSD test, $p<.05)$, whereas older adults did not $(p>.05)$. 


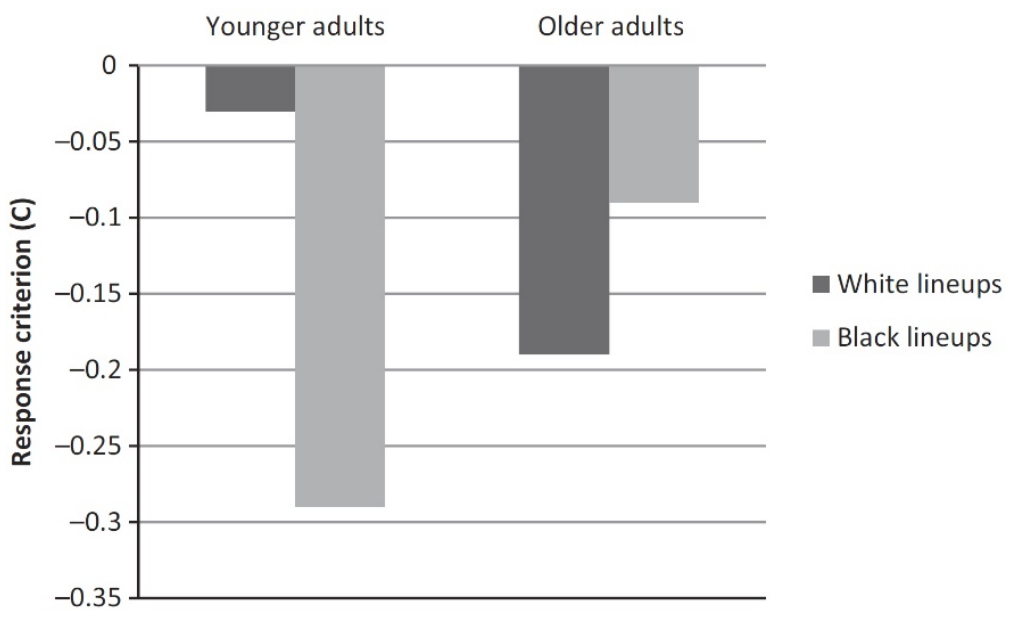

Figure 2. Mixed-model ANOVA for older versus younger adults' response criterion for White and Black lineups.

To examine the effects of age and lineup type for both Black and White lineups on response criterion, two separate two-way ANOVAs were conducted. For White lineups, neither main effects nor the two-way interaction reached significance (all $F[1,155]<1, p=\mathrm{ns}$ ). For Black lineups, however, although there were no significant main effects for either age group or lineup type, there was a significant age group $\times$ lineup type interaction, suggesting a criterion shift, $F(1,155)=4.94, p<.05, \eta^{2}=.03$. For Black lineups, younger adults had more of a liberal response bias for simultaneous lineups $(M=-0.45, S E=0.13)$ compared to sequential lineups $(M=-0.12, S E=0.14)$ similar to results in previous research (Meissner et al., 2005). Contrary to this previous research (Meissner et al., 2005), older adults had more of a liberal response bias for sequential lineups $(M=-0.26, S E=0.17)$ compared to simultaneous lineups $(M=0.07, S E=0.16)$.

\section{Contact with other groups}

Younger adults had more contact with other racial/ethnic groups than older adults $F(1,141)$ $=5.52, p<.05, \eta^{2}=.04$. To examine the relationship between interracial contact and memory for other-race faces, we examined separate correlations by age group between MEI scores and recognition accuracy for Black lineups. For younger adults, there were no significant correlations for discrimination accuracy $r(90)=.16, p=.12$, nor response criterion $r(90)=-.06$, $p=.60$. On the other hand, there was a negative correlation between response criterion and MEI; older adults demonstrated a response criterion shift toward saying "yes" and selecting a photograph for Black lineups $r(53)=-.45, p<.001$, as MEI scores increased (more contact with other groups). There was not a significant correlation for MEI and discrimination accuracy for older adults $r(53)=-.12, p=.41$.

\section{Confidence}

To explore whether confidence was differently related to performance by age and race, confidence levels for Black and White lineups were computed by averaging the confidence 
levels, respectively, for each race. A mixed-model ANOVA was conducted to examine the effects of age on confidence for White versus Black lineups. As expected, there were main effects for age, $F(1,145)=8.32, p<.01, \eta^{2}=.05$, and race, $F(1,145)=16.57, p<.01, \eta^{2}=.10$; however, the two-way interaction was not significant. Specifically, younger adults $(M=4.61$, $S E=0.12)$ were more confident than older adults $(M=4.06, S E=0.15)$, and participants were more confident for White lineups $(M=4.50, S E=0.10)$ than Black lineups $(M=4.17$, $S E=0.10)$. We also explored whether confidence levels differed by lineup type using a mixed-model ANOVA. There was not a significant two-way race $\times$ lineup type interaction, $F(1,145)=1.20, p=.28, \eta^{2}=.01$, therefore we examined separate effects of lineup type on Black and White lineups using a one-way ANOVA. Participants demonstrated confidence differences between simultaneous and sequential lineups for White lineups $F(1,152)=5.24$, $p<.05, \eta^{2}=.03$, such that confidence levels were higher for White simultaneous $(M=4.78$, $S E=1.01)$ than White sequential lineups $(M=4.32, S E=1.42)$. Lineup type did not yield any significant differences for Black lineups $F(1,152)=0.67, p=.42, \eta^{2}=.01$.

We also examined the confidence-accuracy (C-A) relationship by correlating correct decisions (identifying the target in TP lineups; rejecting the lineup in TA lineups) and confidence within each condition. Across all conditions, confidence was a better predictor of accuracy for younger than older participants. For younger adults, there was a medium positive C-A relationship for White lineups in the simultaneous condition $r(48)=.34, p<.05$, and a marginal positive correlation for Black lineups in the simultaneous condition $r(45)=.28$, $p=.06$. For younger adults in the sequential lineup, there was a medium positive C-A relationship for White lineups in the sequential condition $r(43)=.31, p<.05$, but not a significant correlation for Black lineups in the sequential condition $r(44)=.16, p=.30$. These results suggest that for younger adults, confidence is a better predictor of accuracy for own-race than other-race identifications, as well as for simultaneous than for sequential lineups. For older adults in the simultaneous condition, there was not a significant C-A relationship for either White lineups $r(33)=-.06, p=.76$ or Black lineups $r(32)=-.06, p=.74$. In the sequential lineups, older adults did not have a significant C-A relationship for White lineups $r(29)=.11, p=.57$; but there was a medium to large positive C-A relationship for Black lineups $r(28)=.50, p<.01$.

\section{Discussion}

The present research examined whether the ORB varied as a function of participants' age, which allowed us to test the cohort and interracial contact hypotheses. Meissner and Brigham's (2001) meta-analysis found that contact played a small, yet reliable role in explaining the ORB and that the influence of contact on the ORB has increased over time. As such, more recent studies (from the 1990s) in Meissner and Brigham's metaanalysis found a stronger mediating role for contact, while also finding a decrease in the role of negative racial attitudes. One explanation for this may reflect a refinement in the measurement of contact that distinguishes between quality and quantity of contact. Another may be due to cohort effects because opportunities for interracial contact have increased (Chance \& Goldstein, 1996), which can be explored cross-sectionally by examining older adults who lived 
before, during, and after the civil rights movement of the mid-1950s, late-1960s, and comparing them to younger adults who have lived their entire lives after the civil rights movement.

In general, we found support for the ORB in both older and younger adults; however, discrimination accuracy for own-race versus other-race faces was different for the two age groups, suggesting that younger adults had better discrimination accuracy than older adults overall, but that younger adults also showed a larger difference between discrimination accuracy for White and Black lineups. Although a larger difference in discrimination accuracy could be an indication of a more pronounced ORB, our data suggest that in part, younger adults are just more accurate overall. As Figure 1 illustrates, young adults' discrimination accuracy with other-race lineups was roughly equal to older adults' discrimination accuracy for own-race lineups. In examining hits and false alarms, younger adults were both more accurate at identifying targets (hits) and were less likely to identify a target in TA lineups (false alarms) - especially for White lineups, in which they had more hits than false alarms. Additionally, despite the interaction, older adults' discrimination scores still showed a significant ORB. In contrast, older adults' response bias (measured by C) did not evince an ORB, whereas young adults' response bias showed the typical ORB pattern (i.e., more liberal for other-race than for own-race lineups).

Older adults reported having less contact with other groups than younger adults, but contact was related only to ORB measures for older adults. Contrary to the contact theory hypothesis, older adults with more contact demonstrated a criterion shift and were more likely to say "yes" and select a photograph for Black lineups. One explanation could be that older adults with more contact were also more confident, and hence more likely to say "yes" falsely and select a photograph; however, this notion was not supported by the data because the MEI was not related to confidence levels for older adults. Moreover, the MEI may not have validly measured contact with our target race because the MEI measures contact with other "races and ethnicities" generally and not specifically contact with Blacks. Previous research using the MEI within ORB research similarly found little support for the contact hypothesis; however, these authors substituted other "races and ethnicities" with "Blacks" (Bornstein et al., 2013). Meissner and Brigham (2001) suggested that one reason researchers may find a weak relationship between contact and the ORB is that measurement may not be variable enough to detect differences. As such, future research should test other sources or scales for measuring contact with other races.

We also examined factors known to influence identification performance, such as type of lineup presentation (Memon \& Gabbert, 2003a; Steblay et al., 2011) and the presence or absence of a target in the lineup (Memon \& Bartlett, 2002; Steblay et al., 2011; Wilcock \& Bull, 2010). Despite robust findings for the ORB in previous research, few studies have examined the ORB using a fully crossed design. Previous research has noted that although some have identified a "sequential superiority effect" in which sequential lineups may reduce false alarms, sequential lineups may actually just create a criterion shift in which participants make fewer choices (thus, decreasing hits as well) and having no effect on discrimination accuracy (Clark, 2012; Ebbesen \& Flowe, 2002; Meissner et al., 2005). To extend previous studies in this area, we used a hybrid facial recognition paradigm in which par- 
ticipants were presented with multiple faces and then asked to identify previously perceived faces in both TA and TP lineups. This paradigm allowed multiple data points for each participant to compute SDT estimates of discrimination accuracy and response criterion.

We found some support in accordance with previous research (Meissner et al., 2005). Lineup type did contribute to a criterion shift, but only for Black lineups, an effect that was moderated by age group. Younger adults demonstrated a criterion shift in the direction that was expected for Black lineups (a more liberal response bias for simultaneous versus sequential lineups). Older adults, conversely, demonstrated a criterion shift in the opposite direction for Black lineups (a more liberal response bias for sequential lineups versus simultaneous lineups). Unlike previous research (Meissner et al., 2005), lineup type also affected discrimination accuracy. For both age groups and both race lineups, discrimination accuracy was better for simultaneous versus sequential lineups.

Perhaps the greater memory demands of sequential lineups with other-race faces, which require absolute judgments without context, lead to a more liberal response bias (more choosing) for older adults and greater discrimination accuracy for simultaneous lineups over sequential lineups. Research has found that older adults may have more false alarms if stimuli are high in perceived similarity because older adults rely on familiarity more than contextual information (Searcy et al., 1999). In our study, we presented multiple faces, as opposed to a single perpetrator from a crime scene. Perhaps the inclusion of multiple faces, which were intentionally similar and for which there was little context to assist with source monitoring (Lindsay \& Johnson, 1989), made it difficult for older adults to make the absolute judgments from memory that sequential lineups facilitate. Research suggests that the type of paradigm used to study face identification either exerts no effect or larger effects for more naturalistic paradigms (Penrod \& Bornstein, 2007). Nonetheless, future research should directly compare whether there are age differences as a result of research paradigm and the mechanisms that underlie any differences.

To explore whether confidence levels were related to any of these results, we also included confidence measures for each lineup. In our sample, participants were more confident in lineups of their own race then lineups of another race; and younger adults were more confident than older adults. Our results confirm previous findings. Others have found that confidence levels were stronger for own-race identifications than for other-race identifications (Chiroro \& Valentine, 1995; Wright, Boyd, \& Tredoux, 2001). Although metacognition literature has found that older adults tend to be overly confident compared to younger adults, Moulin, James, Perfect, and Jones (2003) concluded in their review that older adults tend to be less confident than younger adults in eyewitness memory recall, likely because of concerns that older adults have in being perceived less credibly.

With respect to the predictive ability of confidence on accuracy, our data suggest that there were some significant C-A relationships. In general, younger adults had a significant C-A relationship across all conditions except for Black lineups in the sequential condition. On the other hand, older adults demonstrated a strong positive C-A relationship only for Black sequential lineups. These findings demonstrate that younger adults have somewhat greater insight into their abilities (or inabilities) to make lineup identifications because 
younger adults had a more consistent C-A relationship across all conditions, which is consistent with other research showing an age-related decline in metacognitive abilities (Pansky, Goldsmith, Koriat, \& Pearlman-Avnion, 2009).

Despite younger adults' more consistent C-A relationship, overall older adults demonstrated the strongest C-A relationship for Black sequential lineups. As previous research has indicated (Memon \& Gabbert, 2003a), older adults perform poorly when given sequential TP lineups. Perhaps older adults also possess similar insight into their own abilities (or inabilities) when making cross-race identifications in sequential lineups. Given that older adults preferentially rely upon relative judgments (Memon \& Gabbert, 2003a; Steblay et al., 2011) and familiarity-based recognition (Yonelinas, 2002) when making identifications, it is possible that attempting to make cross-race identifications in a cognitively taxing sequential identification task inhibits older adults' ability, which they are aware of, as reflected by lower confidence ratings. In other words, when making identifications in Black sequential lineups, older adults are doubly disadvantaged (and apparently aware of these disadvantages) because they are being asked to identify a target of a less familiar race using a lineup type (i.e., sequential) that is less likely to elicit familiarity-based judgments (Meissner et al., 2005; Yonelinas, 2002).

\section{Limitations and future directions}

In this study, we did not include data from non-White participants, so we could not examine a complete crossover effect (e.g., Black and White participants viewing both Black and White faces). Therefore, we were not able to determine if the pattern of findings would be reciprocated in a non-White sample. Although "single-race" ORB studies are not uncommon and largely predict findings of studies using multiple races/ethnicities, differences do sometimes appear (Meissner \& Brigham, 2001); hence, future research should examine the ORB in older adults using a complete cross-race method and further explore the contact hypothesis. In addition, participants in the current research did not witness an episodic event. Most research on the ORB uses a facial recognition paradigm, in which participants view a series of faces before making recognition judgments on one face at a time (Meissner $\&$ Brigham, 2001). The procedure used here was something of a hybrid, where participants viewed several faces but then made lineup decisions, a forensically valid task. This hybrid procedure allows for examining discrimination accuracy and response bias as well as identification performance (e.g., Evans et al., 2009). Future research should assess the generalizability of the present findings to eyewitness memory paradigms (i.e., crime scene presentation), especially given older adults' difficulty in processing complex visual scenes (Hommel, Li, \& Li, 2004; Oken, Kishiyama, \& Kaye, 1994).

Another limitation is that all of the stimuli pictures were of young adults; therefore, the own-age bias in which individuals are better at recognizing faces of people their own age, as opposed to different age groups, may be a concern (Anastasi \& Rhodes, 2005; Wright \& Stroud, 2002). Although age differences between the accuracy of older and younger adults is a robust finding in the literature, there is not much literature on whether the own-age bias affects the ORB. As a result, the main effects between age groups in the current study should be interpreted with caution. Future research should examine whether the magnitude of the ORB differs when targets and foils include both younger and older adults. 


\section{Conclusion}

Years of research have demonstrated that younger adults and children are able to better recognize same-race faces as opposed to other-race faces, yet only one study-published more than three decades ago-has examined whether this bias also exists for older adults. Therefore, the current research not only fills a gap in the eyewitness research with a timely inclusion of older adult participants (Brank, 2007) but does so using a full diagnostic design (Steblay et al., 2011). The findings suggest that older adults should be more fully examined in eyewitness research because some of the current notions about ORB are not the same for younger and older adults. For instance, older adults demonstrated a different criterion shift pattern than younger adults for Black lineups. In addition, confidence ratings were less predictive of accuracy for older adults than younger adults. The current study provides further evidence of the need in eyewitness research to either include older adults as participants or to limit the applicability of findings when only younger adult participants are included.

Funding - This research was supported in part by grants from the University of Nebraska-Lincoln Layman Award awarded to the fourth author and the American Psychology-Law Society, Minority Affairs Committee, Access to Psychology and Law Experience (APPLE) Program awarded to the second author.

\section{References}

Anastasi, J. S., \& Rhodes, M. G. (2005). An own-age bias in face recognition for children and older adults. Psychonomic Bulletin \& Review, 12, 1043-1047. doi: 10.3758/BF03206441

Bartlett, J. C., \& Leslie, J. E. (1986). Aging and memory for faces versus single views of faces. Memory \& Cognition, 14, 371-381. doi: 10.3758/BF03197012

Bartlett, J. C., \& Memon, A. (2007). Eyewitness memory in young and older eyewitnesses. In R. L. Lindsay, D. F. Ross, J. Read, \& M. P. Toglia (Eds.), The handbook of eyewitness psychology, Vol II: Memory for people (pp. 309-338). Mahwah, NJ: Lawrence Erlbaum.

Bennett, L. B., \& Brigham, J. C. (2005). The development of the "cross-race effect" in children's face recognition memory (Unpublished manuscript). Florida State University, Tallahassee, FL.

Bornstein, B. H. (1995). Memory processes in elderly eyewitnesses: What we know and what we don't know. Behavioral Sciences and the Law, 13, 349-363. doi: 10.1002/bsl.2370130303

Bornstein, B. H., Laub, C. E., Meissner, C. A., \& Susa, K. J. (2013). The cross-race effect: Resistant to instructions. Journal of Criminology, Advance online publication. doi: 10.1155/2013/ 745836

Brank, E. M. (2007). Elder research: Filling an important gap in psychology and law. Behavioral Sciences and the Law, 25, 701-716. doi: 10.1002/bsl.780

Brigham, J. C. (2008). The role of race and racial prejudice in recognizing other people. In C. WillisEsqueda (Ed.), Motivational aspects of prejudice and racism (pp. 68-110). New York, NY: Springer. doi: 10.1007/978-0-387-73233-6_4

Brigham, J. C., \& Barkowitz, P. (1978). Do "they all look alike"? The effect of race, sex, experience, and attitudes on the ability to recognize faces. Journal of Applied Social Psychology, 8, 306-318. doi: 10.1111/j.1559-1816.1978.tb00786.x 
Brigham, J. C., Bennett, L., Meissner, C. A., \& Mitchell, T. L. (2007). The influence of race on eyewitness memory. In R. L. Lindsay, D. F. Ross, J. Read, \& M. P. Toglia (Eds.), The handbook of eyewitness psychology, Vol II: Memory for people (pp. 257-281). Mahwah, NJ: Lawrence Erlbaum.

Brigham, J. C., Maass, A., Snyder, L. D., \& Spaulding, K. (1982). Accuracy of eyewitness identifications in a field setting. Journal of Personality and Social Psychology, 42, 673-681. doi: 10.1037//00223514.42.4.673

Brigham, J. C., \& Malpass, R. S. (1985). The role of experience and contact in the recognition of faces of own- and other-race persons. Journal of Social Issues, 41, 139-155.

Brigham, J. C., \& Williamson, N. L. (1979). Cross-racial recognition and age: When you're over 60, do they still "all look alike"? Personality and Social Psychology Bulletin, 5, 218-222. doi: 10.1177/ 014616727900500220

Byatt, G., \& Rhodes, G. (1998). Recognition of own-race and other-race caricatures: Implications for models of face recognition. Vision Research, 38, 2455-2468. doi: 10.1016/S0042-6989(97)00469-0

Carstensen, L. L., Isaacowitz, D. M., \& Charles, S. T. (1999). Taking time seriously: A theory of socioemotional selectivity. American Psychologist, 54, 165-181. doi: 10.1037/0003-066X.54.3.165

Chance, J. E., \& Goldstein, A. G. (1996). The other-race effect and eyewitness identification. In S. Sporer, R. S. Malpass, \& G. Koehnken (Eds.), Psychological issues in eyewitness identification (pp. 153-176). Hilsdale, NJ: Lawrence Erlbaum.

Chiroro, P. M., Tredoux, C. G., Radaelli, S., \& Meissner, C. A. (2008). Recognizing faces across continents: The effect of within-race variations on the own-race bias in face recognition. Psychonomic Bulletin \& Review, 15, 1089-1092. doi: 10.3758/PBR.15.6.1089

Chiroro, P., \& Valentine, T. (1995). An investigation of the contact hypothesis of the own-race bias in face recognition. The Quarterly Journal of Experimental Psychology, 48A, 879-894. doi: 10.1080/1464 0749508401421

Clark, S. E. (2012). Costs and benefits of eyewitness identification reform: Psychological science and public policy. Perspectives on Psychological Science, 7, 238-259. doi: 10.1177/1745691612439584

Cross, J. F., Cross, J., \& Daly, J. (1971). Sex, race, age, and beauty as factors in recognition of faces. Perception \& Psychophysics, 10, 393-396. doi: 10.3758/BF03210319

Donaldson, W. (1992). Measuring recognition memory. Journal of Experimental Psychology: General, 121, 275-277.

Doob, A. N., \& Kirshenbaum, H. M. (1973). The effects on arousal of frustration and aggressive films. Journal of Experimental Social Psychology, 9(1), 57-64. doi: 10.1016/0022-1031(73)90062-0

Ebbesen, E. B., \& Flowe, H. D. (2002). Simultaneous v. sequential lineups: What do we really know? (Unpublished manuscript). University of California, San Diego, CA.

Evans, J., Marcon, J. L., \& Meissner, C. A. (2009). Cross-racial lineup identification: Assessing the potential benefits of context reinstatement. Psychology, Crime \& Law, 15(1), 19-28. doi: 10.1080/ 10683160802047030

Feinman, S., \& Entwisle, D. R. (1976). Children's ability to recognize other children's faces. Child Development, 47, 506-510. doi: 10.2307/1128809

Fulton, A., \& Bartlett, J. C. (1991). Young and old faces in young and old heads: The factor of age in face recognition. Psychology and Aging, 6, 623-630. doi: 10.1037/0882-7974.6.4.623

Garrett, B. L. (2011). Convicting the innocent: Where criminal prosecutions go wrong. Cambridge, MA: Harvard University Press. 
Glanzer, M., \& Adams, J. K. (1990).The mirror effect in recognition memory: Data and theory. Journal of Experimental Psychology: Learning, Memory, and Cognition, 16(1), 5-16. doi: 10.1037/0278-7393 .16.1.5

Goldstein, A. G., \& Chance, J. E. (1985). Effects of training on Japanese face recognition: Reduction of the other-race effect. Bulletin of the Psychonomic Society, 23, 211-214.

Gronlund, S. D., Goodsell, C. A., \& Andersen, S. M. (2012). Lineup procedures in eyewitness identification. In L. Nadel \& W. P. Sinnott-Armstrong (Eds.), Memory and law (pp. 59-83). New York, NY: Oxford University Press.

Hommel, B., Li, K. Z. H., \& Li, S.-C. (2004). Visual search across the life span. Developmental psychology, 40, 545-558. doi: 10.1037/0012-1649.40.4.545

Jackiw, L. B., Arbuthnott, K. D., Pfeifer, J. E., Marcon, J. L., \& Meissner, C. A. (2008). Examining the cross-race effect in lineup identification using Caucasian and First Nations samples. Canadian Journal of Behavioral Science/Revue. Canadienne des Sciences du Comportement, 40(1), 52-57. doi: 10.1037/0008-400x40.1.52

Klobuchar, A., Steblay, N. K. M, \& Caligiuri, H. L. (2006). Improving eyewitness identifications: Hennepin county's blind sequential lineup pilot project. Cardozo Public Law, Policy, E Ethics Journal, 4, 381-413.

Koehnken, G., Malpass, R. S., \& Wogalter, M. S. (1996). Forensic applications of line-up research. In S. L. Sporer, R. S. Malpass, \& G. Koehnken (Eds.), Psychological issues in eyewitness identification (pp. 205-231). Mahwah, NJ: Lawrence Erlbaum.

Lindsay, D. S., \& Johnson, M. K. (1989). The eyewitness suggestibility effect and memory for source. Memory E Cognition, 17, 349-358. doi: 10.3758/BF03198473

MacLin, O. H., Van Sickler, B. R., MacLin, M., \& Li, A. (2004). A re-examination of the cross-race effect: The role of race, inversion, and basketball trivia. North American Journal of Psychology, 6, 189-204.

Marcon, J. L., Meissner, C. A., Frueh, M., Susa, K. J., \& MacLin, O. H. (2010). Perceptual identification and the cross-race effect. Visual Cognition, 18, 767-779. doi: 10.1080/13506280903178622

McDonnell, G. P., Bornstein, B. H., Laub, C. E., Mills, M., \& Dodd, M. D. (2014). Perceptual processes in the cross-race effect: Evidence from eyetracking. Basic and Applied Social Psychology, Advance online publication. 1-16.

Meissner, C. A., \& Brigham, J. C. (2001). A meta-analysis of the verbal overshadowing effect in face identification. Applied Cognitive Psychology, 15, 603-616. doi: 10.1002/acp.728

Meissner, C., Tredoux, C., Parker, J., \& MacLin, O. (2005). Eyewitness decisions in simultaneous and sequential lineups. Memory $\mathcal{E}$ Cognition, 33, 783-792. doi: 10.3758/BF03193074

Memon, A., \& Bartlett, J. C. (2002). The effect of verbalization on face recognition in young and old adults. Applied Cognitive Psychology, 16, 635-650. doi: 10.1002/acp.820

Memon, A., \& Gabbert, F. (2003a). Improving the identification accuracy of senior witnesses: Do prelineup questions and sequential testing help? Journal of Applied Psychology, 2, 341-347. doi: 10.1037/ 0021-9010.88.2.341

Memon, A., \& Gabbert, F. (2003b). Unravelling the effects of sequential presentation in culprit-present lineups. Applied Cognitive Psychology, 17, 703-714. doi: 10.1002/acp.909

Moulin, C. J., James, N., Perfect, T. J., \& Jones, R. W. (2003). Knowing what you cannot recognise: Further evidence for intact metacognition in Alzheimer's disease. Aging, Neuropsychology, and Cognition, 10, 74-82. 
Oken, B. S., Kishiyama, S. S., \& Kaye, J. A. (1994). Age-related differences in visual search task performance: Relative stability of parallel but not serial search. Journal of Geriatric Psychiatry and Neurology, 7, 163-168.

Palmer, M. A., \& Brewer, N. (2012). Sequential lineup presentation promotes less-biased criterion setting but does not improve discriminability. Law and Human Behavior, 36, 247-255. doi: 10.1037/ h0093923

Pansky, A., Goldsmith, M., Koriat, A., \& Pearlman-Avnion, S. (2009). Memory accuracy in old age: Cognitive, metacognitive, and neurocognitive determinants. European Journal of Cognitive Psychology, 21, 303-329. doi: 10.1080/09541440802281183

Pastore, R. E., Crawley, E. J., Berens, M. S., \& Skelly, M. A. (2003). “Nonparametric" A' and other modern misconceptions about signal detection theory. Psychonomic Bulletin and Review, 10, 556-569. doi: 10.3758/BF03196517

Penrod, S., \& Bornstein, B. (2007). Generalizing eyewitness reliability research. In R. L. Lindsay, D. F. Ross, J. Read, \& M. P. (Eds.), The handbook of eyewitness psychology, Vol II: Memory for people (pp. 529-556). Mahwah, NJ: Lawrence Erlbaum.

Pezdek, K., Blandon-Gitlin, I., \& Moore, C. (2003). Children's face recognition memory: More evidence for the cross-race effect. Journal of Applied Psychology, 88, 760-763. doi: 10.1037/0021-9010 .88.4.760

Pezdek, K., O'Brien, M., \& Wasson, C. (2012). Cross-race (but not same-race) face identification is impaired by presenting faces in a group rather than individually. Law and Human Behavior, 36, 488. doi: 10.1037/h0093933

Platz, S. J., \& Hosch, H. M. (1988). Cross-racial/ethnic eyewitness identification: A field study. Journal of Applied Social Psychology, 18, 972-984. doi: 10.1111/j.1559-1816.1988.tb01187.x

Ramirez, M. (1991). Psychotherapy and counseling with minorities: A cognitive approach to individual and cultural differences. Elmsford, NY: Pergamon Press.

Rice, G. E., \& Meyer, B. J. (1986). Prose recall: Effects of aging, verbal ability, and reading behavior. Journal of Gerontology, 41, 469-480.

Searcy, J. H., Bartlett, J. C., \& Memon, A. (1999). Age differences in accuracy and choosing in eyewitness identification and face recognition. Memory \& Cognition, 27, 538-552. doi: 10.3758/BF03211547

Searcy, J., Bartlett, J. C., \& Memon, A. (2000). Influence of post-event narratives, line-up conditions and individual differences on false identification by younger and older witnesses. Legal and Criminological Psychology, 5, 219-235. doi: 10.1348/135532500168100

Shipley, W. C. (1967). Shipley institute of living scale. Los Angeles, CA: Western Psychological Services.

Slone, A. E., Brigham, J. C., \& Meissner, C. A. (2000). Social and cognitive factors affecting the ownrace bias in Whites. Basic and Applied Social Psychology, 22(2), 71-84. doi: 10.1207/1532483005 1036162

Smith v. State, 388 Md. 468 (2005).

Sporer, S. L. (2001). Recognizing faces of other ethnic groups: An integration of theories. Psychology, Public Policy, and Law, 7, 36-97. doi: 10.1037/1076-8971.7.1.36

Stanislaw, H., \& Todorov, N. (1999). Calculation of signal detection theory measures. Behavior Research Methods, Instruments, \& Computers, 3, 137-149.

State v. Henderson, 27 A.3d 872 (2011).

Steblay, N. K., Dysart, J. E., \& Wells, G. L. (2011). Seventy-two tests of the sequential lineup superiority effect: A meta-analysis and policy discussion. Psychology, Public Policy, and Law, 17(1), 99-139. doi: $10.1037 / \mathrm{a} 0021650$ 
U.S. v. Brown, 471 F.3d 802 (2006).

U.S. v. Ford, 683 F.3d 761 (2012).

Valentine, T., Pickering, A., \& Darling, S. (2003). Characteristics of eyewitness identification that predict the outcome of real lineups. Applied Cognitive Psychology, 17, 969-993.

Verde, M. F., Macmillan, N. A., \& Rotello, C. M. (2006). Measures of sensitivity based on a single hit rate and false alarm rate: The accuracy, precision, and robustness of $d^{\prime}, A_{z}$, and $A^{\prime}$. Perception and Psychophysics, 68, 643-654. doi: 10.3758/BF03208765

Weber, N., \& Brewer, N. (2004). Confidence-accuracy calibration in absolute and relative face recognition judgments. Journal of Experimental Psychology: Applied, 10, 156-172. doi: 10.1037/1076-898X .10 .3 .156

Wells, G. L., Memon, A., \& Penrod, S. D. (2006). Eyewitness evidence: Improving its probative value. Psychological Science in the Public Interest, 7, 45-75.

Wilcock, R., \& Bull, R. (2010). Novel lineup methods for improving the performance of older eyewitnesses. Applied Cognitive Psychology, 24, 718-736. doi: 10.1002/acp.1582

Wright, D. B., Boyd, C. E., \& Tredoux, C. G. (2001). A field study of own-race bias in South Africa and England. Psychology, Public Policy, and Law, 7(1), 119-133. doi: 10.1037/1076-8971.7.1.119

Wright, D. B., \& Stroud, J. N. (2002). Age differences in lineup identification accuracy: People are better with their own age. Law and Human Behavior, 26, 641-654. doi: 10.1023/A:1020981501383

Wylie, L. E., Patihis, L., McCuller, L. L, Davis, D., Brank, E. M., Loftus, E. F., and Bornstein, B. H. (2013). Misinformation effects in older versus younger adults: A meta-analysis and review. In M. Toglia, D. Ross, \& J. Pozzulo (Eds.), The elderly eyewitness in court (pp. 38-66). UK: Psychology Press.

Yonelinas, A. P. (2002). The nature of recollection and familiarity: A review of 30 years of research. Journal of Memory and Language, 46, 441-517.

Zachary, R. A. (1991). The manual of the Shipley Institute of Living Scale. Los Angeles, CA: Western Psychological Services.

Zane, N., \& Mak, W. (2003). Major approaches to the measurement of acculturation among ethnic minority populations: A content analysis and an alternative empirical strategy. In Acculturation: Advances in theory, measurement, and applied research, 39-60. Retrieved from http://psychology .ucdavis.edu/aacdr/pubs/zane021.pdf 